\title{
Policy evaluation in parliament: interest groups as catalysts
}

$$
\begin{array}{r}
\text { International Review of Administrative } \\
\text { Sciences } \\
0(0) \text { I-I7 } \\
\text { C) The Author(s) } 2018 \\
\text { Reprints and permissions: } \\
\text { sagepub.co.uk/journalsPermissions.nav } \\
\text { DOI: I0.I I 77/00208523 I 775046। } \\
\text { journals.sagepub.com/home/ras }
\end{array}
$$

@SAGE

\author{
Frédéric Varone \\ University of Geneva, Department of Political Science and \\ International Relations, Switzerland
}

\section{Pirmin Bundi}

University of Bern, Institute of Political Science, Switzerland

\section{Roy Gava}

University of Geneva, Department of Political Science and International Relations, Switzerland

\begin{abstract}
Members of Parliament (MPs) request policy evaluations and use the resultant findings to inform law-making and hold the government to account. Since most elected representatives have developed strong ties to interest groups, one might wonder whether these privileged relationships influence MPs' parliamentary behavior. This study investigates how MPs' affiliations to groups affect their demand for policy evaluations. Empirical evidence shows that, regardless of respective party or individual characteristics, MPs are more likely to request evaluations in those policy domains where they have a group affiliation. This effect holds even when controlling for a classical measure of MP's policy specialization, such as legislative committee membership. These findings suggest that ties between MPs and specific types of interest group should be considered when explaining parliamentary behavior across different policy domains.
\end{abstract}

\section{Point for practitioners}

To influence the policymaking process, interest groups participate in consultation procedures and parliamentary hearings, they lobby elected officials and deliver policy expertise to decision-makers. These advocacy strategies are well studied. This article

\section{Corresponding author:}

Frédéric Varone, University of Geneva, Unimail Geneva, 12II Switzerland.

Email: frederic.varone@unige.ch 
innovates by showing that, in addition, interest groups foster the development of policy evaluations. MPs affiliated to an interest group active on a specific issue are likely to request policy evaluations in that policy domain. Interest groups strengthen the parliamentary demand for evaluation studies and, thus, may potentially contribute to the accountability of government and public administration.

\section{Keywords}

citizen groups, economic groups, evaluation, policy domains

\section{Introduction}

Elected Members of Parliament (MPs) are both legislators and controllers of the government. MPs require information to fulfill these law-making and oversight functions. Policy evaluation is one potential source of such information, since a policy evaluation aims to deliver new insights about the quality of a policy design, the progress of its implementation and its final impacts on economy and society. MPs are the stakeholders par excellence of policy evaluations (Speer et al., 2015), whose results should reduce MPs' uncertainty about policy effects and, furthermore, the information asymmetry between the government and the parliament.

Empirical studies have demonstrated that MPs activate different parliamentary instruments (e.g. questions, interpellations, motions) to initiate an evaluation, to monitor an evaluation process and to ask about concrete evaluation findings. In addition, MPs directly use the knowledge provided to improve their own decisionmaking and to hold government to account (Bundi, 2016; Jacob et al., 2015; Speer et al., 2015; Zwaan et al., 2016). Previous research delivered three findings on the factors explaining why an MP will demand or use a policy evaluation report. First, MPs' attention to evaluation is unequally distributed between policy sectors (e.g. great attention to education or health policy versus low attention to public finance or defense policy). Second, MPs belonging both to the opposition and to the political parties forming the government (coalition) request evaluations: the former need evaluative evidence to scrutinize and challenge the government, and the latter instrumentalize evaluation to highlight and publicize the policy activities and performance of their own ministers. Finally, socioeconomic as well as partisan characteristics of MPs (e.g. age, education, seniority in parliament, party membership) seem to have little to no influence at all on an MP's evaluation activity. In contrast, membership in an oversight committee as well as a positive attitude towards evaluation in general increases MPs' motivation to request evaluation reports (Bundi, 2016).

The role of interest groups as a factor explaining the parliamentary requests of policy evaluations remains unexplored. This is an important research gap since evaluation reports are by no means the only source of policy-relevant information 
for MPs. Interest groups, which often represent the target groups or beneficiaries of the policies to be evaluated, are a valued source of expertise. For instance, interest groups deliver information through lobbying activities targeting individual MPs, actively participate in official consultations procedures, and present testimonies during the hearings organized by legislative committees. By means of these advocacy strategies, interest groups provide their expertise as an 'exchange good' to access the parliamentary venue (Bouwen, 2002).

At the same time, interest groups also encourage MPs to evaluate specific policies. Evaluation might be highly rewarding for an interest group if the resulting evaluation allows for keeping an issue important to the group constituency on the parliamentary agenda, revising a law in a policy direction that better fits the group preferences, or (re)legitimating the implementation tasks formally delegated to the group. Various motivations lead interest groups to get involved in parliamentary evaluation practice and this study considers the ties between MPs and groups to investigate the following research question: What is the impact of interest groups on MPs' behavior related to evaluation requests? This question is not only relevant from an empirical and theoretical point of view. It is also highly sensitive from a normative stance. If interest groups do have a significant impact on the parliamentary evaluation practice, then this could also have major implications for the democratic accountability of policy processes and elected officials.

The article is structured as follows. The theoretical section introduces the research hypotheses. The methodological section explains why the Swiss parliament is selected as a most likely case to test these hypotheses and shows that the survey data collected are representative. It also presents the operationalization of the main variables. The results section focuses on one major empirical finding: MPs are more likely to demand policy evaluations in the policy domains of their interest group affiliations. This effect holds even when controlling for a classical measure of policy specialization such as legislative committee membership. Finally, the concluding section puts this study into a broader perspective and identifies the next research steps.

\section{Theoretical framework}

Both MPs and interest groups try to influence policy-making in order to realize the policy preferences of their respective constituencies. However, major differences between them are that interest groups do not compete for office, they cannot make authoritative decisions and must cooperate with MPs in order to influence legislative outputs. By contrast, MPs hold formal decision-making power, but regularly interact with interest groups to increase their information resources and secure their re-election. The MP-group linkage is frequently understood as an exchange relationship. Groups provide technical expertise about the policy issue at stake and political information about the policy position of their constituency to elected MPs, or make contributions to their electoral campaign. As a counterpart, MPs grant groups privileged access to an institutional venue (e.g. a hearing at a 
legislative committee) where policy decisions are made, or even commit themselves to actively supporting legislative proposals promoted by groups (Berkhout, 2013).

Surveys of both interest groups (Rasmussen and Landeboom, 2013) and MPs (Wonka, 2017) indicate that such partnerships are reported as crucial by both sides. Previous scholarship has also demonstrated that the information transmitted by groups to MPs predominantly concerns the feasibility and implementation of policies (Baumgartner et al., 2009:132-33). Furthermore, when groups deliver policy-relevant information, they target parties which share their ideological preferences and policy positions. Linkages are established between like-minded groups and MPs (Hall and Deardorff, 2006: 75): business groups predominantly support the legislative activities of MPs belonging to right parties, while public interest groups primarily help MPs from left parties to design workable policies (Gava et al., 2017; Otjes and Rasmussen, 2017; Wonka, 2017). The present study contributes to this literature by looking more deeply at the impact of MP-group links on parliamentary evaluation practice. More concretely, we argue that interest groups foster parliamentary evaluation demand.

\section{Interest groups as catalysts}

Beyond providing their own policy expertise and political intelligence to likeminded MPs, interest groups also try to convince 'their' MPs to demand evaluations that will deliver additional policy-relevant information. Three main reasons motivate interest groups to advocate policy evaluation. First, evaluation might be instrumentalized as a strategic tool to monitor all stages of the policy cycle. Evaluation requests concern the (ex ante) regulatory impact assessments of intended policies, the (in itinere) monitoring of implementation outputs or the (ex post) measurement of policy effects. Consequently, the political use of evaluation findings supports or hinders the agenda-setting of a new policy, and legitimates either the continuation, revision or termination of an existing policy (Eberli, 2017: 3). Interest groups encourage MPs to request evaluation with the deliberate aim of pre-empting a new policy that contradicts the group's preferences or, on the contrary, of supporting policy outcomes that deliver benefits concentrated on their members (Wilson, 1980). The following evaluation demand illustrates this strategy: 'Before taking any additional measures to regulate the mortgage market and home ownership, the Federal Council (i.e. the government) shall evaluate the effects of the measures taken in the last two years in this field, and consult widely with interested parties' (Motion by MP O. Feller; 6 May 2014). This parliamentary request was introduced by a right-wing Swiss MP, who was affiliated to several business groups active in the real estate market, as a tactical move to delay any policy change towards more state regulation on the mortgage market.

Second, like-minded groups and MPs often try to build 'iron triangles' with public agencies sharing their policy preferences. If the consolidation of such policy monopoly with a trustworthy agency is not feasible, then interest groups and MPs face a classical agency problem. They have to delegate policy implementation to a 
public administration whose positions may differ from their own preferences. This results in a series of common agency problems for the interest groups and their MPs. The latter, as principals, cannot be sure whether the government and its agencies implemented the policies in the way they were intended (McCubbins, 2014). Hence, MPs have strong incentives to control the government. In doing so, evaluations seem to be an instrument for MPs to oversee agencies and to provide accountability since agencies have to report on their activities and provide information to MPs during evaluations (Bundi, 2016). As a consequence, MPs not only gather information about a certain policy, but also about how it has been implemented by the administration. For instance, one MP requested that the government evaluate the legal basis of the placement of foster children, as most of the placement companies are said to focus on their own profit rather than on the children's benefit (Interpellation by MP J. Fehr, 15 December 2011). This evaluation request was strongly influenced by a group committed to the interests of foster children. Both the MP and the group feared that the well-being of the children would be in danger without a sound implementation of the policy (Bundi, 2017: 5).

Third, performing a policy evaluation is costly. On the one hand, individual MPs suffer from resource scarcity (i.e. time, money) when attempting to monitor all developments in a policy field. On the other hand, groups do not always have the resources or necessary access to public records (e.g. on policy outputs) to produce their own expertise. Evaluation knowledge produced by the state has thus one clear appealing characteristic for interest groups: by piggybacking on the public sector, groups can outsource the cost of producing policy expertise. Furthermore, if the evaluation results are eventually in line with the group's position, the policy expertise produced by the state can be presented as relatively authoritative and objective during policy struggles. Even if the evalution results does not correspond with the interest group's position, MPs still have the possibility of misusing the evaluation findings, either by manipulating or intentionally misinterpreting them (Weiss, 1979). In sum, interest groups encourage MPs to demand policy evaluation to assist 'their' MPs, as policy allies, in achieving their shared policy preferences. The first hypothesis reads as follows:

H1: The more MPs have affiliations to interest groups, the more they demand evaluation requests.

\section{Economic versus citizen groups}

We have to note, however, that interest groups are likely to differ in their incentives for relying on policy evaluations performed by the state. First, economic groups (e.g. peak-level business associations) are probably better endowed with financial resources and political staff than citizen groups (e.g. environmental or humanitarian groups). They are more likely to provide MPs with private expertise, 
whose content can be controlled by the group itself, privileging it over policy evaluations produced by the state. To counterbalance this comparative disadvantage, citizen groups may resort more often to the evaluation knowledge produced by the state. The incentives for piggybacking on state resources is higher for citizen groups than for economic groups.

Second, evaluation reports are often discussed in the parliamentary arena and are covered by the media as well. Evaluation reports thus contribute to raising public attention about policy effects, supporting the outsider lobbying tactics privileged by cause groups rather than by sectional groups (Binderkrantz, 2005: 706; Kriesi et al., 2007: 66). Indeed, the value of private expertise provided by business groups declines as MPs, media and citizens care about the policy under evaluation (Culpepper, 2011: 178). In short, the second hypothesis postulates:

$\mathrm{H} 2$ : MPs with affiliations to economic groups demand less evaluation requests than MPs with affiliations to citizen groups.

\section{Policy specialization of groups and MPs}

The two previous hypotheses may be further specified, since most MPs specialize in one or a few policy domains. Indeed, MPs are members of legislative committees focusing on specific policy issues and negotiate legislative proposals that are eventually adopted by the plenary assembly. Membership in a permanent legislative committee fosters the specialization of MPs (Gilligan and Krehbiel, 1987; Searing, 1987; Strøm, 1990), who acquire a policy expertise that also grants them power and prestige among party peers and the media. Accordingly, policy specialists are more likely to request a policy evaluation on their domain of competence than MPs who are not members of the relevant legislative committee.

Furthermore, interest groups prefer to lobby MPs sitting on the legislative committees that address the policy issues which directly concern their group's members (Bowler and Farrell, 1995; Marshall, 2015: 323; Yordanova, 2009). One might thus expect a topical congruence between the competence area of a committee and the domain of activity of the groups with which MPs are affiliated. Indeed, Eichenberger and Mach (2017) showed that, within the Swiss parliament, MPs' formal ties to groups strongly reflect the policy responsibilities of the respective committee. This substantive match is partially due to the strategic recruitment of legislative committee members by interest groups, since many ties between groups and MPs develop after MPs are assigned to specific committees.

These privileged relationships between committee members and groups are consequential. An MP who has accepted a seat on the board of a specific group arguably has a strong incentive to be proactive, within the relevant legislative committee, on the policy issues that are of interest to the constituency of 'his/ her' group. In other words, we argue that MP-group ties have an additional impact on parliamentary evaluation requests, beyond the MP's policy 
specialization through committee membership, which will be introduced as a control variable in the statistical models. Within a given legislative committee, MPs with ties to groups will probably demand more policy evaluations than MPs not affiliated to groups. The third research hypothesis stipulates:

H3: Within a policy domain, MPs with more affiliations to interest groups are more likely to demand policy evaluations than MPs with fewer or no affiliations to interest groups.

In a nutshell, the theoretical framework claims that interest groups do matter for MPs' evaluation requests. However, citizen groups are more willing than economic groups to encourage MPs to demand evaluation evidence and, furthermore, each group concentrates on the policy issues that are of interest to their own members.

\section{Research design}

The present empirical study is based on a survey of all federal MPs in Switzerland, who were asked to report on the importance of evaluation activities for their parliamentary work. This section discusses three issues raised by this research design: the selection of the Swiss case, the representativeness of the MPs survey, and the empirical measurement of the key variables.

\section{Case selection}

The Swiss parliament is a most likely case to test the research hypotheses. First, and in comparative perspective, the Swiss parliament enjoys a strong institutional position vis-à-vis the government in terms of agenda-setting power, competences of parliamentary committees, decision rights and instruments to control the executive (Döring, 1995; Lüthi, 2014; Siaroff, 2003). Switzerland is, together with the Scandinavian countries, a political system where parliament's co-decision rights are strong and the government's control of the legislative agenda is weak (Vatter, 2014: 298-99). Therefore, the demands of policy evaluation are highly relevant for Swiss MPs and, more generally, for the balance of power between executive and legislative venues.

Second, policy evaluation is strongly institutionalized in Switzerland (Varone et al., 2005). A general evaluation clause was introduced into the constitution 15 years ago: 'The Federal Assembly shall ensure that federal measures are evaluated with regard to their effectiveness' (Article 170 of the Federal Constitution of April 1999). Sector-specific evaluation clauses can be found in primary or secondary legislation and urge MPs to request evaluations in various policy domains. Furthermore, parliamentary Control Committees commission the Parliamentary Control of the Administration to evaluate the legality, expediency and effectiveness of selected public policies. The Federal Audit Court is also habilitated to compare 
the costs and benefits of policy measures. The Swiss parliamentary evaluation culture is among the most advanced in all OECD countries (Jacob et al., 2015).

Third, the Swiss parliament is an interesting case due to its 'militia character'. For decades, the Federal Assembly was basically 'composed of amateurs who combine their professional activities with their parliamentary duties' (Kriesi, 2001: 60). The lack of MP resources resulting from this militia system increases MPs' dependence on interest groups (Bailer, 2011; Bütikofer, 2013). In fact, the information resources that Swiss MPs have at their disposal are limited from a comparative perspective (Schnapp and Harfst, 2005; Vatter, 2014). However, permanent legislative committees have been institutionalized since 1992, and MPs have become increasingly competent in those policy fields covered by the specialized committees to which they belong (Pilotti, 2012). If MPs are more professional nowadays, then interest groups could be expected to invest more intensively in the parliamentary venue to influence them (Christiansen et al., 2016; Eichenberger and Mach, 2017).

Finally, Swiss MPs are requested to declare their formal ties (i.e. seating in a group's board) with interest groups. The register of interests is a rich source of observational data showing that the average number of interest ties per MP has more than doubled over the last decade, from 3.5 in 2000 to 7.6 in 2011 (Gava et al., 2017). In sum, the Swiss parliament offers an ideal setting for investigating the influence of interest group advocacy on MPs' evaluations requests.

\section{Survey}

The second methodological issue concerns the representativeness of the survey that we conducted in 2014 among the 245 federal MPs (Eberli et al., 2014). With 112 MPs answering the survey, the response rate (45.7 percent) is relatively high for legislative surveys in Switzerland and abroad (Bütikofer, 2013; Deschouwer and Depauw, 2014). Table 2 (in the online Appendix) compares the participants of the survey with all invited MPs regarding different characteristics. The four major parties (Swiss People's Party, Social Democrats, Liberals, and Christian Democrats) are reasonably represented in the survey (i.e. 80.4 percent in the survey to 80.8 percent in parliament). Concerning MPs' gender, language and age, the sample is relatively balanced as well. MPs with parliamentary seniority between eight and 11 years are underrepresented in the survey sample (13.4 percent to 18.0 percent). In contrast, almost no differences can be observed regarding the committee memberships and the number of parliamentary interventions which were submitted by the MPs. Hence, no self-selection bias invalidates the empirical analysis (Bundi et al., 2016).

\section{Measurement of variables}

The survey data measure MPs' activities related to policy evaluation. As MPs may have a broad understanding of what policy evaluation is, the survey introduced an 
explicit definition: 'In this survey, evaluations are interpreted as studies, reports or other documents, which assess a state's measure in a systematic and transparent way with respect to their effectiveness, efficiency or fitness for purpose.' The dependent variable investigated is the demand for policy evaluations. MPs were asked to report whether they have requested policy evaluations in different policy domains by means of parliamentary interventions during the last four years (i.e. 1 March 2010-20 June 2014).

To capture relationships between MPs and interest groups, we make use of the official register of MPs' interests: Swiss MPs have been required since 1985 to declare all their mandates (e.g. executive boards seats) with companies and interest groups. For the period 2012-14, the year-based 'raw' inventory of the register allows us to identify 602 dyads between the 112 MPs who participated in the survey, and 544 interest groups. We capture two distinct but complementary dimensions of interest groups. First, we assess the diversity of interest groups by means of two main types (Binderkrantz et al., 2015): (1) Economic groups encompass private firms, business associations (e.g. the Industry and Trade Association), occupational groups (e.g. the Swiss Medical Association) and unions at the sector and peak levels (e.g. the Federation of Trade Unions). (2) Citizen groups correspond to public interest groups, whose members focus on the attainment and protection of common goods (e.g. environmental groups or humanitarian organizations) and identity groups (e.g. representing women, tenants, drivers, etc.), leisure groups (e.g. Scout groups, orchestras' support associations, Swiss Olympics, etc.), religious groups (e.g. Swiss Evangelical Alliance or abbeys' support associations) and associations representing institutional actors, such as Swiss cities.

Second, we rely on the 20 policy domains of the Comparative Agendas Project (http://www.comparativeagendas.net) to code the main sector of activity for each interest group. We then aggregate these data in 10 broader categories of policy domains in order to match those areas with the policy domains of the parliamentary interventions: Foreign Affairs and Security, Public Finance, Welfare, Economy, Education, Energy, Spatial Planning and Infrastructure, Health, Justice and Migration, and State Affairs. For example, the first evaluation request presented above showed that an MP affiliated to interest groups active in the real estate market demanded an evaluation of the regulation of the mortgage market. In this case, both the policy content of the evaluation request and the main area of activity of the interest groups affiliated to the MP concern the same policy domain, namely 'economy'. It is worth noting that the policy domains do not overlap with the two group types. For example, within the health policy domain, economic groups such as business associations representing private health insurances, or occupational groups representing medical professions, cohabitate with citizen groups such as public interest groups representing all patients, or identity groups representing people with specific disabilities. Table 3 in the online Appendix provides an overview of the policy domains.

Finally, information about the control variables stems from the survey of MPs and includes gender, age, education, language region, occupational background, ${ }^{1}$ 
party affiliation, Lower and Upper House, professionalization, membership in oversight and legislative committees, and parliamentary experience. Table 4 in the online Appendix presents the operationalization of all variables.

In order to assess the impact of group affiliations in specific policy domains as formulated in $\mathrm{H} 3$, the survey data set has been stacked in a matrix that derives from a normal one, as the units of analysis do not represent a single MP, but an MP $\times$ Policy domain combination (Van der Eijk et al., 2006). Hence, each MP is represented by as many cases as there are policy domains (i.e. 10 domains in this case). An entry was generated for every policy domain that indicated whether an MP has submitted a parliamentary request in a certain policy domain. By using this approach, we can estimate the influence of groups in different policy domains. Since the data are nested in two different levels (MP, policy domain), the study uses a multi-level analysis in order to estimate the models. Moreover, we assume that the variance of the second level is varying, which is why we use a random intercept model to test variables on the two levels. As the outcome of the endogenous variable is binary, we use a logistic regression model. The following model is used to estimate the MP's likelihood of submitting a parliamentary request:

$$
Y_{i j}=\gamma_{00}+u_{0 i j}+e_{i j}
$$

Where $Y$ is likelihood of an MP ( $i$ ) to demand an evaluation in a policy domain $(j)$, while $\gamma_{00}$ stands for the random intercept and $u_{0 i j}$ for the overall regression slopes. $e_{i j}$ refers to the random residual error term at two levels.

\section{Results}

More than 50 percent of the 112 MPs participating in the survey demanded an evaluation in the four years prior to the survey (i.e. between 2010 and 2014). About 20 percent of the MPs submitted one parliamentary request to demand an evaluation. One-third of MPs even submitted several requests. However, the evaluation demand is unequally distributed among the policy domains. While the MPs frequently demanded an evaluation in the policy domains Welfare and Economy, the areas Education, Energy, and Public Finances were less often targeted by parliamentary requests.

Model 1 tests whether the number of interest groups linked to an MP has an influence on the general evaluation demand (see Table 1). Results indicate that the number of ties to distinct interest groups does not influence an MP's likelihood of requesting an evaluation. The first research hypothesis is thus not supported by empirical evidence. In contrast, some socioeconomic characteristics influence MPs' likelihood of submitting parliamentary requests in order to evaluate a policy measure. Women are more likely to demand evaluations than men, so are MPs from the minority French- and Italian-speaking regions. Moreover, MPs with an 
Table I. Individual and policy domain random effects models.

\begin{tabular}{|c|c|c|c|}
\hline & (I) & $(2)$ & (3) \\
\hline \multirow[t]{2}{*}{ Women } & $1.280 * *$ & $1.257^{* *}$ & $0.619 * *$ \\
\hline & $(0.532)$ & $(0.538)$ & $(0.25 \mathrm{I})$ \\
\hline \multirow[t]{2}{*}{ Age } & 0.006 & 0.002 & 0.004 \\
\hline & $(0.024)$ & $(0.026)$ & $(0.012)$ \\
\hline \multirow[t]{2}{*}{ Education } & -0.028 & -0.029 & -0.001 \\
\hline & $(0.1 \mathrm{II})$ & $(0.11 \mathrm{I})$ & $(0.055)$ \\
\hline \multirow[t]{2}{*}{ Latin } & $1.030 *$ & $1.014^{*}$ & $0.529 * *$ \\
\hline & $(0.533)$ & $(0.537)$ & $(0.248)$ \\
\hline \multirow[t]{2}{*}{ Independent Work Logic } & $-0.920 * *$ & $-0.924 * *$ & -0.303 \\
\hline & $(0.46 \mathrm{I})$ & $(0.463)$ & $(0.228)$ \\
\hline \multirow[t]{2}{*}{ Center-Right Party } & 0.445 & 0.466 & 0.256 \\
\hline & $(0.488)$ & $(0.502)$ & $(0.243)$ \\
\hline \multirow[t]{2}{*}{ Upper House } & -0.492 & -0.474 & $-0.708^{*}$ \\
\hline & $(0.739)$ & $(0.750)$ & $(0.400)$ \\
\hline \multirow[t]{2}{*}{ Professionalization } & -0.367 & -0.433 & -0.565 \\
\hline & $(1.536)$ & $(1.535)$ & $(0.770)$ \\
\hline \multirow[t]{2}{*}{ Parliamentary Experience } & -0.026 & -0.029 & 0.001 \\
\hline & $(0.052)$ & $(0.053)$ & $(0.026)$ \\
\hline \multirow[t]{2}{*}{ Oversight Committee } & 0.034 & 0.093 & 0.382 \\
\hline & $(0.495)$ & $(0.507)$ & $(0.249)$ \\
\hline \multirow[t]{2}{*}{ Committee } & & & $1.480 * * *$ \\
\hline & & & $(0.230)$ \\
\hline \multirow[t]{2}{*}{ Total Interest Group } & 0.069 & 0.089 & -0.016 \\
\hline & $(0.055)$ & $(0.068)$ & $(0.030)$ \\
\hline \multirow[t]{2}{*}{ Economic Group } & & -0.332 & 0.067 \\
\hline & & $(0.66 I)$ & $(0.321)$ \\
\hline \multirow[t]{2}{*}{ Citizen Group } & & -0.164 & 0.388 \\
\hline & & $(0.745)$ & $(0.425)$ \\
\hline \multirow[t]{2}{*}{ Policy Domain } & & & $0.165^{* * * *}$ \\
\hline & & & $(0.064)$ \\
\hline \multirow[t]{2}{*}{ Constant } & $-0.692 * * *$ & -0.198 & $-3.370 * * *$ \\
\hline & $(1.717)$ & $(1.954)$ & $(0.988)$ \\
\hline \multicolumn{4}{|l|}{ Residual variance } \\
\hline \multicolumn{2}{|l|}{ Between $\phi$ (Policy Fields) } & & 0.237 \\
\hline Observations & 95 & 95 & 950 \\
\hline Log Likelihood & -57.532 & -57.360 & $-298.74 \mid$ \\
\hline $\operatorname{LR} \chi^{2}$ & 16.54 & 16.82 & \\
\hline Pseudo $R^{2}$ & & 0.128 & \\
\hline Wald $\chi^{2}$ & & & $65.12 * * *$ \\
\hline
\end{tabular}

independent work logic (e.g. farmers, company owners) are less likely to demand evaluations than MPs with dependent work logic professions. By contrast, parliamentary characteristics (i.e. professionalization, experience, oversight committee, party affiliation) do not affect evaluation demand. 


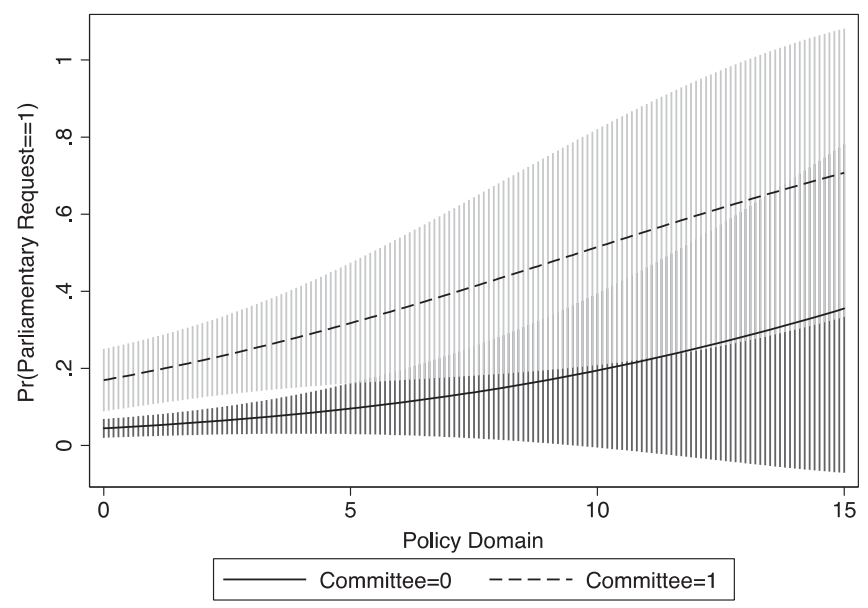

Figure I Predicted probabilities of demanding an evaluation for the policy domain. Note: Predicted probabilities of demanding an evaluation with a parliamentary request, as a function of the policy domain and member of a legislative committee (dashed line) and nonmember of a legislative committee (solid line). The values are calculated for MPs with the following attributes: men, center-right party, German-speaking, independent work logic, nonoversight committee, and Lower House. All other variables are at the median.

Model 2 investigates the impact of MP ties to economic groups versus citizen groups. The estimates of model 2 show that ties to economic or citizen groups do not influence whether an MP demands an evaluation. This result does not provide evidence for the second hypothesis.

Finally, model 3 presents the results of the impact of interest affiliations in specific policy domains. In comparison to policy domains in which MPs do not have any ties to interest groups, MPs with the maximum ties to the interest groups $(n=15)$ have almost a 53.8 percent higher probability of demanding an evalution in this particular policy field. Figure 1 illustrates this empirical finding. The horizontal axis refers to the number of ties in a policy domain, while the y-axis shows the predicted probability to demand an evaluation regarding different policy fields. In order to control for the legislative committee effect, a traditional measure of MP policy specialization, we distinguish between MPs who are members of a legislative committee of a policy domain (dashed line) and those who are not (solid line). MPs' have a 30 percent higher probability of demanding an evaluation in a policy field if they are members of a legislative committee and have interest group affiliations in this policy domain. In contrast, the likelihood is 50 percent higher if the MPs are not members of a policy-specific policy field, but have affiliations to interest groups in this policy domain. Although legislative committee members have a higher probability of demanding an evaluation, the effect also increases with the number of ties to groups in a specific policy domain. Ties to interest 
groups in a certain policy field thus have a positive effect on evaluation requests in this specific policy domain, even though the effect of committee membership is more substantial. The committee effect confirms previous studies showing that MPs want to build a reputation in their area of legislative specialization (Proksch and Slapin, 2011). However, the interest group effect provides new evidence about the motives and incentives driving legislators' demand for policy evaluations. Bundi (2017) shows that MPs' motives to demand policy evaluations are strongly linked to committee membership. While oversight committee members more often demand evaluations in order to obtain information on a policy, legislative committee members seek to change policy outcomes. Our findings suggest that, through their ties with MPs, interest groups may influence the policy agenda by means of policy evaluations. The evidence indicates that the parliamentary behavior of MPs is shaped by their links with interest groups. In sum, the analysis provides strong support for the third hypothesis.

To sum up, the empirical analysis shows that MP-group ties influence parliamentary behavior. However, it is the specialization of groups in specific policy domains that is crucial for the relationship between MPs' affiliations to groups and evaluation demands. As expected by the third hypothesis, MPs demand more evaluations in those policy domains which are most relevant to their groups. Contrary to the first theoretical expectation, the number of ties to different groups does not determine whether an MP will demand an evaluation. Moreover, the type of groups (economic vs. citizen groups) to which MPs are affiliated does not seem to affect the demand for policy evaluations by MPs.

\section{Conclusion}

Previous scholarship on the parliamentary evaluation practice showed that party politics does not explain why some MPs are more likely than others to ask for policy evaluations (Bundi, 2016; Speer et al., 2015). The present study corroborates this finding. Furthermore, it has the added value of proposing an innovative explanation of MPs' motivation to submit an evaluation request, namely the linkages between interest groups and MPs. It is argued that MPs interact with groups sharing their political priorities and policy preferences. Both partners focus on the same policy domain and, accordingly, monitor the legislative developments that affect their respective constituencies. Groups assist MPs to request policy evaluations in specific policy domains and, thus, to perform their oversight function. They provide policy expertise and political intelligence as well as financial resources to MPs who, as their counterpart, introduce evaluation requests about policy issues that are important for the groups' constituencies. This claim is supported by empirical evidence from the Swiss parliament. The positive effect of linkages between MPs and interest groups on evaluation demand in specific policy fields remains present even when controlling for committee membership.

Some policy domains are characterized by the strong presence of economic groups, while citizen groups populate others (Coen and Katsaitis, 2013). 
The very nature of policy domains affects the density and diversity of MP-group ties and, eventually, parliamentary behavior related to policy evaluation. The importance of systematically comparing policy domains has been acknowledged by scholars working on the 'ecology of groups population' (Gray and Lowery, 1996) or on 'Chameleon pluralism' (Richardson and Coen, 2009: 338); it should also be put on the research agenda of parliamentary evaluation studies. This research avenue is also relevant for normative debates on the quality of democratic representation, policy responsiveness and accountability. Indeed, the electoral delegation chain might be broken if, for instance, MPs are closer to the policy preferences of 'their' interest groups than those of their electoral constituency (Giger and Klüver, 2016).

This exploratory article has three limitations that could be overcome by upcoming studies. First, it was argued that Switzerland is a most likely case to test the three research hypotheses since the parliament is institutionally strong vis-à-vis the government, non-professional MPs interact intensively with interest groups, and the policy evaluation culture is well developed. Swiss institutions are an enabling context for the impact of MP-group ties on parliamentary interventions asking for policy evaluations. To assess the external validity of the empirical results presented here, this study should be replicated in Westminster systems, highly professionalized parliaments and countries with a less developed policy evaluation practice.

Second, interest groups are one information source among many for MPs. The policy expertise provided by parliamentary committees, MPs' party staff and civil servants is also relevant for the law-making and oversight functions that MPs fulfill. The influence of interest groups on the parliamentary evaluation practice should thus not be overestimated before these additional information sources are also taken into consideration.

Finally, this study has investigated under which conditions MPs rely on parliamentary instruments to initiate a policy evaluation process. The next logical step would be to scrutinize whether these parliamentary requests translate into concrete evaluation mandates and, eventually, if MPs use the findings of the evaluation reports that are produced to improve legislation and/or to increase the government's accountability. MP-group ties could also play an important role fostering - or, on the contrary hindering - such policy feedback loops. If the policy recommendations from an evaluation report run against the preferences of an interest group, then one can reasonably expect this group to develop an advocacy strategy with counter-arguments to pre-empt the use of evaluation results. So, it would make sense to compare the relative strength of interest groups as evaluation entrepreneurs versus veto players trying to block policymaking based on empirical evaluation evidence.

\section{Acknowledgments}

This work was supported by the Swiss National Science Foundation under grants 100018_149689, FZFSPO_174280 and CRSII1_141893. The authors thank Stefaan Walgrave, Julie Sevenans and the anonymous reviewers for their valuable remarks. 


\section{Supplementary Material}

Tables 2, 3, 4 are available online. Please see http://journals.sagepub.com/home/ras.

\section{Note}

1. Oesch (2006) distinguishes four different types of work logics: independent (selfemployed), technical work logic (work process determined by technical production), organizational work logic (bureaucratic division of labor), and interpersonal work logic (service-based on face-to-face exchange).

\section{References}

Bailer S (2011) People's voice or information pool? The role of, and reasons for, parliamentary questions in the Swiss parliament. Journal of Legislative Studies 17(3): 302-314.

Baumgartner FR, Berry JM, Hojnacki M, Leech BL and Kimball DC (2009) Lobbying and Policy Change: Who Wins, Who Loses and Why. Chicago, IL: Chicago University Press.

Berkhout J (2013) Why interest organizations do what they do: Assessing the explanatory potential of 'exchange' approaches. Interest Groups \& Advocacy 2(2): 227-250.

Binderkrantz A (2005) Interest groups strategies: Navigating between privileged access and strategies of pressure. Political Studies 53: 694-715.

Binderkrantz A, Christiansen PM and Pedersen HH (2015) Interest group access to the bureaucracy, parliament, and the media. Governance 28(1): 95-112.

Bouwen P (2002) Corporate lobbying in the European Union: The logic of access. Journal of European Public Policy 9(3): 365-390.

Bowler S and Farrell DM (1995) The organizing of the European parliament: Committees, specialization and co-ordination. British Journal of Political Science 25(2): 219-243.

Bundi P (2016) What do we know about the demand for evaluations? Insights from the parliamentary arena. American Journal of Evaluation 37(4): 522-541.

Bundi P (2017) Parliamentarians' strategies for policy evaluations. Evaluation and Program Planning. doi: https://doi.org/10.1016/j.evalprogplan.2017.02.003

Bundi P, Varone F, Gava R. and Widmer T (2016) Self-selection and misreporting in legislative surveys. Political Science Research and Methods. doi:10.1017/psrm.2016.35

Bütikofer S (2013) Das Schweizer Parlament. Eine Institution auf der Pfad der Moderne. Eine Analyse der 47. Legislature. Baden-Baden: Nomos.

Christiansen PM, Mach A and Varone F (2016) How corporatist institutions shape the access of citizen groups to policy makers: Evidence from Denmark and Switzerland. Journal of European Public Policy. doi 10.1080/13501763.2016.1268194

Coen D and Katsaitis A (2013) Chameleon pluralism in the EU: An empirical study of the European Commission interest groups density and diversity across policy domains. Journal of European Public Policy 20(8): 1104-1119.

Culpepper PD (2011) Quiet Politics and Business Power: Corporate Control in Europe and Japan. Cambridge: Cambridge University Press.

Deschouwer K and Depauw S (eds) (2014) Representing the People: A Survey Among Members of Statewide and Substate Parliaments. Oxford: Oxford University Press.

Döring H (1995) Time as scarce resource: Government control of the agenda. In: H Döring (ed.) Parliaments and Majority Rule in Western Europe. Frankfurt: Campus, pp. 225-246. 
Eberli D (2017) Tracing the use of evaluations in legislative processes in Swiss cantonal parliaments. Evaluation and Program Planning. doi: https://doi.org/10.1016/j.evalprog plan.2017.02.003

Eberli D, Bundi P, Frey K and Widmer T (2014) Befragung Parlamente und Evaluationen. Ergebnisbericht. Universität Zürich.

Eichenberger S and Mach A (2017) Formal ties between interest groups and members of parliament: Gaining allies in legislative committees. Interest Group \& Advocacy 6(1): $1-21$.

Gava R, Varone F, Mach A, Eichenberger S, Christe J and Chao-Blanco C (2017) Interests groups in parliament: Exploring MPs' interest affiliations (2000-2011). Swiss Political Science Review 23(1): 77-94.

Giger N and Klüver H (2016) Voting against your constituents? How lobbying affects representation. American Journal of Political Science 60(1): 190-205.

Gilligan TW and Krehbiel K (1987) Collective decisionmaking and standing committees: An informational rationale for restrictive amendment procedures. Journal of Law, Economics \& Organization 3(2): 287-335.

Gray V and Lowery D (1996) The Population Ecology of Interest Representation: Lobbying Communities in the American States. Ann Arbor, MI: University of Michigan Press.

Hall RL and Deardorff AV (2006) Lobbying as legislative subsidy. American Political Science Review 100(1): 69-84.

Jacob S, Speer S and Furubo J-E (2015) The institutionalization of evaluation matters: Updating the International Atlas of Evaluation 10 years later. Evaluation 21(1): 6-31.

Kriesi H (2001) The federal parliament: The limits of institutional reform. West European Politics 24(2): 59-76.

Kriesi H, Tresch A and Jochum M (2007) Going public in the European Union. Action repertoires of Western European collective political actors. Comparative Political Studies 40(1): 48-73.

Lüthi R (2014) Parlament. In: P Knoepfel, I Papadopoulos, P Sciarini, A Vatter and S Häusermann (eds) Handbuch der Schweizer Politik. Zurich: NZZ Libro, pp. 169-192.

Marshall D (2015) Explaining interest group interactions with party group members in the European parliament: Dominant party groups and coalition formation. Journal of Common Market Studies 53(2): 311-329.

McCubbins MD (2014) Common agency? Legislatures and bureaucracies. In: M Shane, T Saalfeld and K Strøm (eds) The Oxford Handbook of Legislative Studies. Oxford: Oxford University Press, pp. 567-590.

Oesch D (2006) Redrawing the Class Map: Stratification and Institutions in Britain, Germany, Sweden and Switzerland. New York: Palgrave Macmillan.

Otjes S and Rasmussen A (2017) The collaboration between interest groups and political parties in multi-party democracies: Party system dynamics and the effect of power and ideology. Party Politics 23(2): 96-109. doi: 10.1177/1354068814569046

Pilotti A (2012) Les parlementaires suisses entre démocratisation et professionnalisation (1910-2010). Université de Lausanne.

Proksch SO and Slapin JB (2011) Parliamentary questions and oversight in the European Union. European Journal of Political Research 50(1): 53-79.

Rasmussen A and Landeboom G-J (2013) Interest group-party linkage in the twenty-first century: Evidence from Denmark, the Netherlands and the United Kingdom. European Journal of Political Research 52: 264-289. 
Richardson J and Coen D (2009) Institutionalisation and managing intermediation in the EU. In: D Coen and J Richardson (eds) Lobbying the EU. Oxford: Oxford University Press, pp. 325-338.

Schnapp K-U and Harfst P (2005) Parlamentarische Informations- und Kontrollressourcen in 22 westliche Demokratien. Zeitschrift für Parlamentsfragen 36: 348-370.

Searing DD (1987) New roles for postwar British politics: Ideologues, generalists. specialists, and the progress of professionalization in Parliament. Comparative Politics 19(4): $431-452$.

Siaroff A (2003) Varieties of parliamentarism in the advanced industrial democracies. International Political Science Review 24: 445-464.

Speer S, Pattyn V and de Peueter B (2015) The growing role of evaluation in parliaments: Holding government accountable? International Review of Administrative Sciences 81(1): 37-57.

Strøm K (1990) A behavioral theory of competitive political parties. American Journal of Political Science 34(2): 565-598.

Van der Eijk C, Van der Brug W, Kroh M and Franklin M (2006) Rethinking the dependent variable in voting behavior: On the measurement and analysis of electoral utilities. Electoral Studies 25(3): 424-447.

Varone F, Jacob S and De Winter L (2005) Polity, politics and policy evaluation in Belgium. Evaluation 11(3): 253-273.

Vatter A (2014) Das politische System der Schweiz. Baden-Baden: Nomos.

Weiss CH (1979) The many meanings of research utilization. Public Administration Review 39(5): 426-431.

Wilson JQ (1980) The Politics of Regulation. New York: Basic Books.

Wonka A (2017) German MPs and interest groups in EU multilevel policy-making: The politics of information exchange. West European Politics 40(5): 1004-1024.

Yordanova N (2009) The rationale behind committee assignment in the European Parliament: Distributive, informational and partisan perspectives. European Union Politics 10(2): 253-280.

Zwaan P, Van Voorst S and Mastenbroek E (2016) Ex-post legislative evaluations in the European Union: Questioning the use of evaluation as instruments for accountability. International Review of Administrative Sciences 82(4): 674-693.

Frédéric Varone is Professor of Political Science at the University of Geneva. His research interests include comparative public policy and interest groups.

Pirmin Bundi is Lecturer and Post-Doctoral Researcher at the University of Bern. His research interests include policy evaluation and parliamentary behavior.

Roy Gava is Lecturer and Post-Doctoral Researcher at the University of Geneva. His research interests include financial regulation and legislative production. 